\title{
Women's self-care behavior and its relationship with social capital in Yazd, Iran
}

\author{
Hamideh Shiri-Mohammadabad and Seyed Alireza Afshani * (D)
}

\begin{abstract}
Background: Research on factors affecting self-care is scarce. The social factors, in particular, have not been yet investigated in Iran. Therefore, the present study aimed to investigate the relationship between self-care and social capital among women.

Methods: The participants were 737 women who were living in the marginal, middle and upper areas in the city of Yazd, Iran. Data were collected using a researcher-made self-care questionnaire and Harper's (Off Natl Stat 11:2019, 2019) Social Capital Scale. The data were analyzed using structural equation modeling by SPSS and Amos V24.
\end{abstract}

Results: The results showed that the social capital had significant positive effects on the general self-care behavior of the participants ( $\beta=0.56, p<0.001)$. It also had significant positive effects on the self-care behavior of women living in the marginal $(\beta=0.58)$, middle $(\beta=0.49)$ and upper $(\beta=0.62)$ parts of the city $(p<0.001)$. Besides, the women living in the marginal parts had relatively lower levels of self-care compared to those living in the middle and upper parts of the city. The examination of the fit indices indicated that the model has a good fit (CMIN/DF $=2.087, \mathrm{NFI}=0.921$, $\mathrm{RMSEA}=0.027, \mathrm{CFI}=0.956, \mathrm{TLI}=0.940, \mathrm{GFI}=0.956, \mathrm{IFI}=0.957)$.

Conclusion: The findings of this study demonstrated that social capital has significant positive effects on the general self-care behavior of women. Therefore, improving their self-care can be achieved through promoting their social capital.

Keywords: Social capital, Self-care, Iran, Women

\section{Background}

Self-care is a multidimensional concept that encompasses various aspects of one's personal life $[1,2]$. It has also been conceptualized as a movement [3], a process [4], a set of principles, strategies, or behaviors [2] even abilities [5] with various physical, mental/emotional, spiritual, intellectual, social and recreational dimensions [2, 6-8].

Although there has been an increasing emphasis on self-care in recent years, there is still no general consensus on its definition $[7,9]$. Self-care specifically refers to some deliberate, learned and purposeful practices and

*Correspondence: afshanialireza@yazd.ac.ir

Department of Cooperative and Social Welfare, Faculty of Social Science, Yazd University, Yazd, Iran activities performed by individuals to sustain and promote their health [10-12].

The self-care behavior among women is a highly significant topic in medical sociology and gender studies; however, there is scarce research on it in Iran particularly, in Yazd. With respect to the units of analysis, the dimensions of the self-care and the preventive perspective adopted in the present inquiry, this study can be regarded an initiative investigation into women's self-care behavior in Iran.

Reports published by the Statistical Center of Iran have provided some examples of Iranian women's self-care behaviors. A review of such behaviors indicates that women do not appreciate self-care well. For instance, Iranian women above 15 years spend only " 12 " and "13" minutes per day on "sports" and "cultural and 
recreational activities", respectively; while the same people spend a large fraction of their time (on average $5 \mathrm{~h}$ and $16 \mathrm{~min}$ ) on housekeeping activities [13]. Happiness is an indicator of self-care behavior and according to a UN report, Iran is in an unfavorable condition in terms of happiness (score 4.5; rank 117 out of 156) [14].

No matter where one lives, the birth of a boy or a girl usually has significant impact on all the aspects of one's life, including their health issues; however, the type and the nature of the consequences vary from one society to the other [15]. Gender is held as a socio-cultural criterion, and is considered as one of the basic reasons for inequality in health [16]. Various forms of gender inequality can be seen throughout the world and, in particular, in Iran. Due to the dominance of traditional culture over one's personal and social life, Iranian women are always the witness of different behaviors from those around them. Girls, for instance, soon give up the childish pursuits, find feminine behaviors and become socially accepted to follow the ideal model of a housewife with several children. Women are often considered less significant than men and occupy lower positions, are less likely to be employed than men, face a variety of barriers and inequalities in the job market. In addition, the women's biological differences, their different positions in the social structures, their roles and responsibilities, their position in the family, the persisting shadow of traditions on their personal and family lives and their social power are all parts of the problems with which they have to struggle [17]. For instance, the interaction of genetic, hormonal and physiological issues with inadequate social support, financial poverty, the stresses related to childbirth, the mother and child health, and household responsibilities are among the factors that increase the likelihood of unhealthy behaviors in women, the question that arises here now is whether they can take good care of themselves under such circumstances or not.

Researchers have overlooked social factors influencing human behavior when discussing the importance of selfcare and the vitality of health as a personal achievement that one acquires through their behaviors [18]. Individuals' choices depend on the opportunities that life offers them; hence, one cannot gain a proper understanding of self-care behavior without taking the relevant social factors into account. Social capital is among the social determinants of self-care.

The concept of social capital is strongly based on social relationships [19]. It refers to a set of actual or potential resources associated with a cohesive network of more or less institutionalized relationships of mutual acquaintance and recognition [20]. Social capital can affect an individual's self-care behaviors in different ways. First, it influences one's health behaviors by enhancing rapid diffusion of health-related information, i.e., individuals with desirable social capital can easily adopt healthy norms and control over their deviant behaviors [21]. Second, social capital reinforces social self-help in societies, and enables them to easily work together to solve collective problems such as health issues [22]. It also affects self-care by facilitating access to self-care services, facilities, knowledge and skills [21, 23]. Finally, a wide range of studies have confirmed the effective role of social capital in improving health and self-care behaviors. For instance, in Marume's study [24] of the refugees in Zimbabwe, it was found that social capital has a significant role in improving the refugees' health. In another study on the rural Uttar Pradesh in India by Hasan [25], the results have showed a significant relationship between social capital and self-care. Also, Chong et al. [26] believe that there is a significant positive relationship between social capital and health behaviors among the youth in the suburbs of Malaysia. In line with previous studies, this survey investigated the effectiveness of social capital in improving women's self-care behavior.

\section{Methods \\ Objectives}

This cross-sectional survey assessed the level of self-care in a sample of women in Yazd, Iran and investigated the relationship between women's social capital and self-care behavior.

\section{Study population}

The study population consisted of all the women living in Yazd. Yazd Municipality has divided the city into different neighborhoods (upper, middle and marginal parts) based on previous studies as well as the neighborhoods' characteristics such as the quality of the buildings, the socio-economic characteristics of the residents, the residents' education qualifications, the health and the service indicators [27]. The Sadrabad, Hasanābād and Eskan neighborhoods were considered as the marginal parts; Naiemabad, Azar Yazdi and Razmandegan neighborhoods as the middle parts; and Jomhouri Blvd., Safaeieh and Maskan neighborhoods as the upper parts of Yazd.

The participants were selected from nine different neighborhoods according to the density level in Yazd through a cluster sampling method in proportion to size. To meet this end, at first, the nine neighborhoods in Yazd were considered as nine main clusters. Then, the streets and main squares in each cluster were considered as the block. At last, the participants were randomly selected.

Participants met the inclusion criteria if they were 18-70 years old and were living in the neighborhood for more than 2 years. From each house, only one person was selected. Temporary residence in the neighborhood, 
unwillingness to participate in the study and the presence of problems such as blindness and deafness were among the exclusion criteria.

The questionnaire was completed at home by the household women at the presence of one of the researchers, who tried to collect a sufficient amount of data with regard to the variables of age, employment status, and their educational level.

In order to estimate the sample size, a pilot study was first conducted on 50 women to determine the variance of self-care. Using Cochran's sample size formula (error $=5 \% ; 95 \% \mathrm{CI}$ ), the sample size was then determined as 246 for each of the marginal, middle and upper parts in Yazd. To compensate for incomplete questionnaires and loss to follow-up cases, a total of 250 questionnaires were given to eligible participants residing in each part of the city between June and October 2020. A total of 737 legible questionnaires were collected and analyzed.

\section{Variable measurement Socio-demographic characteristics checklist}

A socio-demographic characteristics checklist was used to collect information about the participants' age (open question), marital status (single, married, or others), educational qualifications (open question) and the number of children (open question).

Social Capital Scale: The social capital was measured through Harper's Social Capital Scale [28]. This 26-item scale consists of dimensions such as social participation (networks), social networks and social support, reciprocity and trust, civic participation and views of the local part. The items are scored on a five-point Likert scale ranging from 1 to 5 . The reliability of the scale is acceptable (Cronbach's alpha $=0.880$ ).

Self-Care Scale: Various researchers have used different variables to measure self-care. Table 1 shows a selection of them.

Considering the operational definitions of the self-care given in research [2, 29-32], in order to measure the selfcare in the present study, we recognized that in different questionnaires, only some dimensions of the self-care have been addressed and some items in some questionnaires are not particularly suitable for our society. Therefore, it was decided to combine the dimensions of these questionnaires and prepare a comprehensive questionnaire. In this regard, 12 copies of the questionnaire were provided to seven experts in the field of sociology, three experts in the field of demography and two experts in the field of psychology. They were then asked to comment on the content validity ratio (CVR) of the questionnaire, i.e. the necessity of the items, as well as the content validity index (CVI) of the questionnaire, i.e. "simplicity and fluency", "relevance, or specificity" and "clarity or transparency" of the items based on the objectives of the study. Finally, the items with CVR equal to and greater than 0.75 and CVI equal to and greater than 0.79 remained in the questionnaire. The final questionnaire consisted of 30 items that would examine the physical, psychological/ emotional, spiritual, intellectual, social and recreational dimensions of women's self-care.

Physical self-care (5 items): It is related to the care of the physical self, and incorporates the strategies to optimize physical function and safety [33].

Psychological self-care (5 items): It encompasses the emotional and cognitive strategies to maintain a positive and compassionate view of the self, negotiate the external demands with internal expectations and identify, accept and express a range of emotions [34].

Spiritual self-care (5 items): It includes the search for meaning and purpose in life, the connection to the religious beliefs, values and practices that give meaning to life [35].

Social self-care (5 items): It refers to the strategies to build meaningful and positive relationships and develop a sense of connection, belonging and support [36].

Recreational self-care (5 items): It refers to participation in enjoyable activities that promote relaxation, rejuvenation, or encourage creativity [9].

Intellectual self-care (5 items with reverse scores): It is related to the exploration of ideas and learning in a creative manner [6].

The dimensions of self-care were measured on a fivepoint scale (1: never, 2: sometimes, 3: often, 4: usually, 5:

Table 1 Assessing self-care in some experimental researches

\begin{tabular}{ll}
\hline Researcher & Dimensions \\
\hline $\begin{array}{l}\text { Dorociak (2015) } \\
\text { The Institute for Func- } \\
\text { tional Medicine (2016) }\end{array}$ & Physical self-care, psychological self-care, spiritual self-care, social self-care and recreational self-care [29] \\
$\begin{array}{l}\text { Clarke (2017) } \\
\text { Saakvitne and Pearlman } \\
\text { (1996) }\end{array}$ & Physical self-care, emotional self-care, social self-care and professional self-care [2] \\
\hline
\end{tabular}


always). The maximum score was 150 and the minimum score was 30. Higher scores indicated a higher level of self-care. Cronbach's alpha of 0.760 was obtained on this scale (Additional file 1).

\section{Statistical analysis}

The socio-demographic variables were analyzed using descriptive statistics (including percentage, frequency, mean and standard deviation). A one-sample t-test was used to compare the differences regarding the participants' self-care levels. Using a structural model, the authors assessed the relationships between the social capital and the self-care behavior among the women residing in the marginal, middle and upper parts of the city. They also compared the intensity of the relationships between the research variables in different parts. The data were analyzed in SPSS Amos v24 using structural equation modeling (SEM).

\section{Results}

\section{Respondents' characteristics}

Of the total of 737 participants in the present study, 558 women $(75.7 \%)$ were married and, by compartmentalizing the parts, married women comprised the majority of women living in the marginal, middle, and upper parts.

The results of the present study revealed that the mean and standard deviation of education qualifications were $12.83 \pm 3.71$. The results also indicated that the women living in the marginal parts had the lowest mean scores $(10.83 \pm 3.75)$. In terms of the number of children, the mean and standard deviation were $1.85 \pm 1.61$. The findings also indicated that the women living in the marginal parts had the highest mean scores $(2.14 \pm 1.75)$ compared to those living in the middle and upper parts of the city.

In addition, the results of the one-way ANOVA showed that there is a significant difference between the women living in the upper, middle and marginal parts of Yazd in terms of the educational qualifications and the number of children $(p<0.01)$; however, no age difference was observed between women living in the upper, middle and marginal parts of Yazd ( $\left.p^{>} 0.05\right)$. The results of the chisquare test showed that there is a significant difference between the women's marital status in different parts, and the percentage of married people in the marginal parts was significantly higher than women living in the upper parts $(p<0.001)$. The demographic characteristics of the respondents are presented in Table 2 .

Based on the results of the one-sample t-test, the minimum and maximum self-care scores were 30 and 150, respectively; thus, the mean score of women's self-care in the marginal, middle and upper parts of Yazd was higher than 90 (theoretical mean). Therefore, the overall level of the participants' self-care was relatively above the average $(p<0.001)$.

In addition, the one-sample t-test was used in order to answer the question "How is the social capital of the women living in the marginal, middle and upper parts of Yazd?". To assess the social capital among the respondents, 24 items were included in the questionnaire. Given that each item had five options, the minimum and the maximum scores were 24 and 120 , respectively. The score 72 was chosen as the theoretical mean. A score of higher than 72 indicates that the respondents' level of social capital is higher than average and a score of lower than 72 indicates that the respondents' level of social capital is lower than average. The result of the one-sample t-test showed that the mean score of the social capital of the women living in the marginal, middle and upper parts was higher than 72 (the theoretical mean). Therefore, in total, the respondents' social capital was above the average $(p<0.001)$ (Table 3$)$.

An independent-sample t-test was also used to compare self-care among employed and unemployed women in the three upper, middle and marginal parts in the city. The results showed no significant difference $\left(p^{>} 0.05\right)$ (Table 4).

\section{The structural model of the self-care}

Using the structural model, the relationship between the social capital and the self-care was examined separately in different parts of Yazd, the outputs were interpreted, and the coefficients of these three groups were compared (Figs. 1, 2, 3, 4).

As shown in Table 5, the social capital had significant positive effects on the general self-care behavior of the participants $(\beta=0.56, p<0.001)$. It also had significant positive effects on the self-care behavior of women living in the marginal $(\beta=0.58)$, middle $(\beta=0.49)$ and upper $(\beta=0.62)$ parts of the city $(p<0.001)$.

In addition, we used the model fit indexes to estimate the model fit, and the models fit the data adequately $(\mathrm{CMIN} / \mathrm{DF}=2.087, \quad \mathrm{NFI}=0.921, \quad \mathrm{RMSEA}=0.027$, $\mathrm{CFI}=0.956, \mathrm{TLI}=0.940, \mathrm{GFI}=0.956, \quad \mathrm{IFI}=0.957$, see Table 6).

\section{Discussion}

Social capital is an important determining factor in population health $[18,37,38]$. It can influence the self-care behavior through several possible causal mechanisms including the influence of social cohesion on healthrelated behaviors, differential procurement of social services, access to resources such as emotional and material support, health information generated by social networks and variations in individuals' access to life opportunities and material resources (e.g., health care, education) 
Table 2 respondents' characteristics

\begin{tabular}{|c|c|c|c|c|}
\hline Variable & Parts & Mean & SD & $p$-value \\
\hline \multirow[t]{4}{*}{ Age } & Marginal & 35.83 & 10.85 & 0.373 \\
\hline & Middle & 35.74 & 11.45 & \\
\hline & Upper & 34.53 & 11.67 & \\
\hline & Full sample & 35.37 & 11.33 & \\
\hline \multirow[t]{4}{*}{ Education qualifications } & Marginal & 10.83 & 3.75 & 0.001 \\
\hline & Middle & 13.62 & 3.43 & \\
\hline & Upper & 13.96 & 3.12 & \\
\hline & Full sample & 12.83 & 3.71 & \\
\hline Marital status & Parts & $\mathbf{n}$ & $\%$ & $p$-value \\
\hline \multirow[t]{4}{*}{ Married } & Marginal & 204 & 83.3 & 0.001 \\
\hline & Middle & 189 & 76.8 & \\
\hline & Upper & 165 & 67.3 & \\
\hline & Full sample & 558 & 75.7 & \\
\hline \multirow[t]{4}{*}{ Single } & Marginal & 33 & 13.5 & \\
\hline & Middle & 55 & 22.4 & \\
\hline & Upper & 73 & 29.8 & \\
\hline & Full sample & 161 & 21.9 & \\
\hline \multirow[t]{5}{*}{ Others } & Marginal & 8 & 3.3 & \\
\hline & Middle & 2 & 0.8 & \\
\hline & Upper & 7 & 2.9 & \\
\hline & Full sample & 17 & 2.3 & \\
\hline & Parts & Mean & SD & $p$-value \\
\hline \multirow[t]{4}{*}{ Number of children } & Marginal & 2.14 & 1.75 & 0.004 \\
\hline & Middle & 1.71 & 1.50 & \\
\hline & Upper & 1.71 & 1.56 & \\
\hline & Full sample & 1.85 & 1.61 & \\
\hline
\end{tabular}

$S D$ standard deviation; variable ranges: age (18-70); marital status (1-3); education qualifications (0-20); number of children (0-11); marginal part ( $n=246)$; middle part $(n=246)$; upper part $(n=245)$; full sample $(n=737)$

Table 3 The output of one-sample t-test on the differences of self-care and social capital of women in the marginal, middle and upper parts of Yazd

\begin{tabular}{llrlll}
\hline Variable & Part & Mean (SD) & $\begin{array}{l}\text { Mean } \\
\text { difference }\end{array}$ & t & p-value \\
\hline Self-care & Marginal & $94.66 \pm 11.49$ & 4.66 & 6.358 & 0.001 \\
& Middle & $97.21 \pm 12.37$ & 7.21 & 9.142 & 0.001 \\
& Upper & $100.20 \pm 14.15$ & 10.20 & 11.291 & 0.001 \\
Social & Marginal & $83.15 \pm 15.18$ & 11.15 & 11.52 & 0.001 \\
capital & Middle & $91.67 \pm 18.53$ & 19.67 & 16.65 & 0.001 \\
& Upper & $87.93 \pm 14.77$ & 15.93 & 16.88 & 0.001 \\
\hline
\end{tabular}

$[39,40]$. Besides, there are factors like socioeconomic factors (e.g., inequality), social network structures (e.g., homogeneity, density) and characteristics of network ties (e.g., frequency of contact, strong/weak ties, reciprocity) which can affect the type of the social capital that is being formed and the individuals' health behaviors [38]. Considering the importance of this issue, the present study aimed to investigate the explanatory role of the social capital on the self-care behaviors of women living in the marginal, middle and upper parts of Yazd.

The results of our study showed that the level of selfcare among the women living in the marginal, middle and upper parts of Yazd was above the average and the women living in the upper parts had a higher level of selfcare compared to the women living in the marginal and middle parts $(p<0.001)$.

The self-care behaviors in different strata and groups are the result of a set of choices that a person chooses based on their social status and life opportunities. In fact, from Weber's point of view, the self-care behavior is the result of a dialectical relationship between life opportunities and lifestyle. Life opportunities are considered as a form of structure that basically reflects the status of one's social class, and weakens and limits their choices. In other 
Table 4 The output of t-test on the differences of self-care of women in the marginal, middle and upper parts of Yazd

\begin{tabular}{|c|c|c|c|c|c|c|}
\hline Variable & Part & Groups & Mean (SD) & Mean difference & $t$ & $p$-value \\
\hline \multirow[t]{6}{*}{ Self-care } & Marginal & Employee & $96.17 \pm 9.00$ & 1.48 & 1.003 & 0.317 \\
\hline & & Unemployed & $94.69 \pm 10.00$ & & & \\
\hline & Middle & Employee & $96.55 \pm 11.68$ & -0.67 & -0.438 & 0.662 \\
\hline & & Unemployed & $97.23 \pm 11.29$ & & & \\
\hline & Upper & Employee & $101.20 \pm 12.29$ & 1.49 & 0.687 & 0.493 \\
\hline & & Unemployed & $100.17 \pm 11.09$ & & & \\
\hline
\end{tabular}

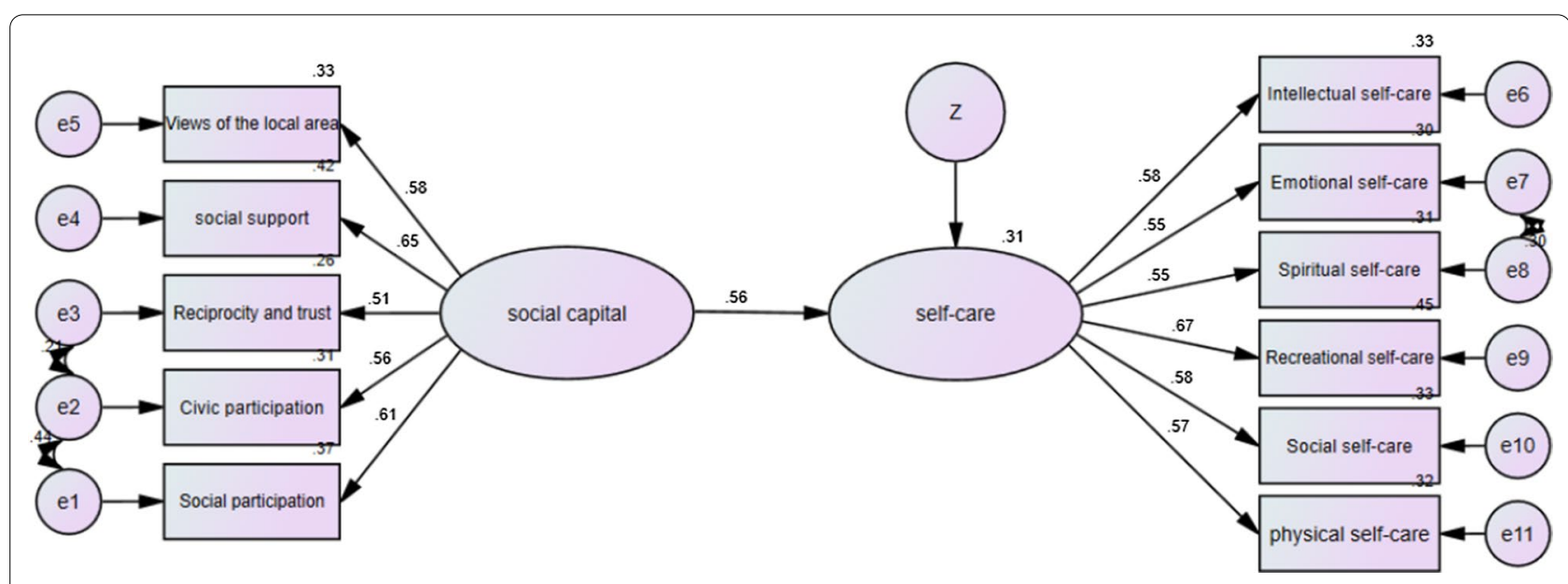

Fig. 1 The model of the relationship between social capital and self-care in the full sample

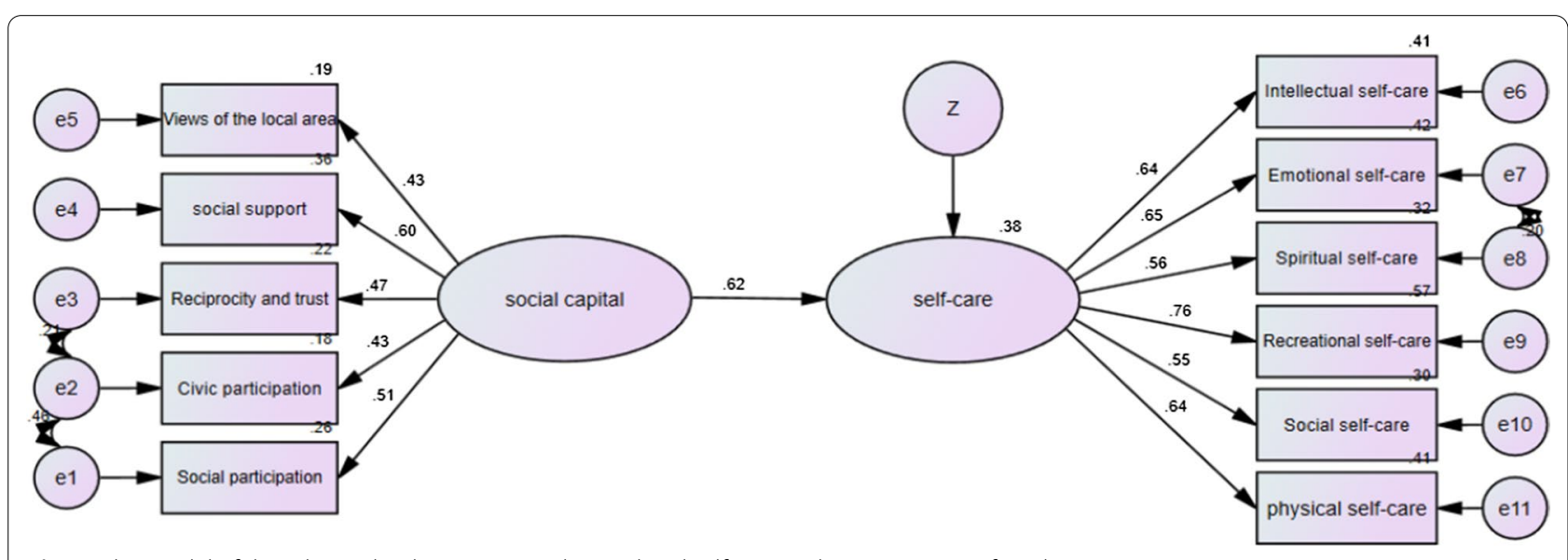

Fig. 2 The model of the relationship between social capital and self-care in the upper parts of Yazd

words, those strata of the society who possess a good life opportunity will be able to participate in physical activities and have more opportunities for relaxation and eat healthier food. However, those strata of the society (for example, the residents of the marginal parts) who do not possess a good position in the social classification will have unhealthier performances due to the constraints that poor life opportunities create for them [41]. According to the results of the present study and the relevant studies [41, 42], it seems that the individuals' position in the social situations has an important role in the possibility or impossibility of the healthy performances in their behaviors. Also, 


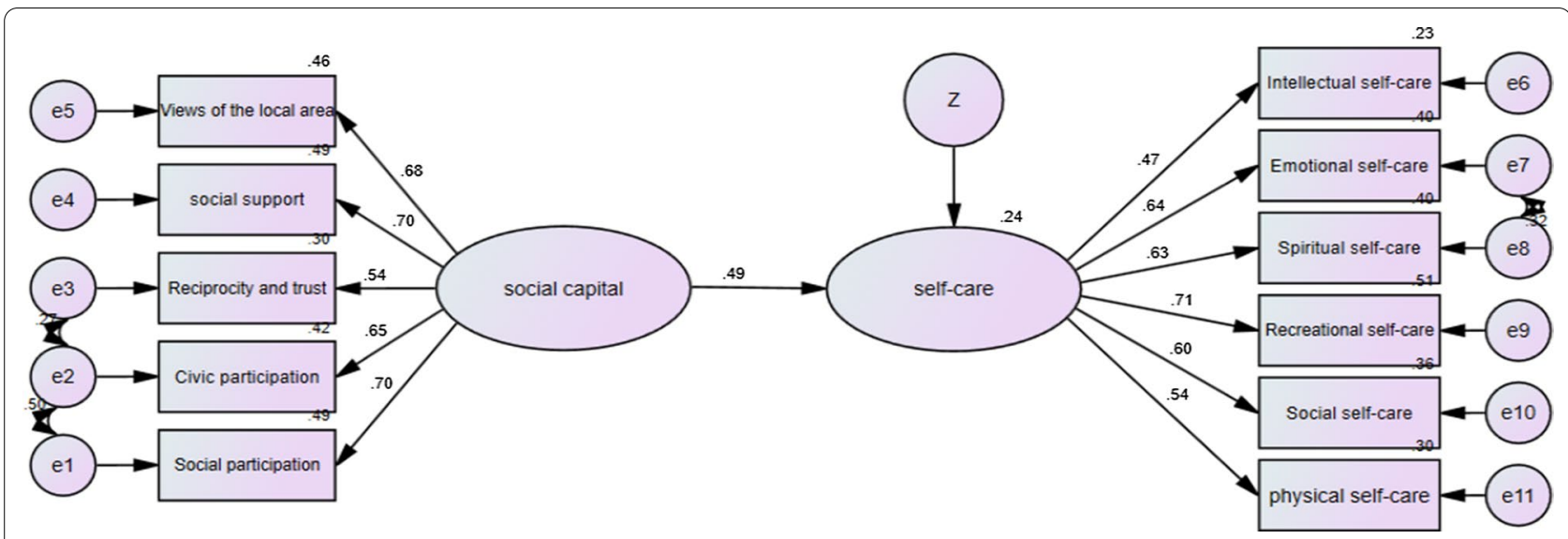

Fig. 3 The model of the relationship between social capital and self-care in the middle parts of Yazd

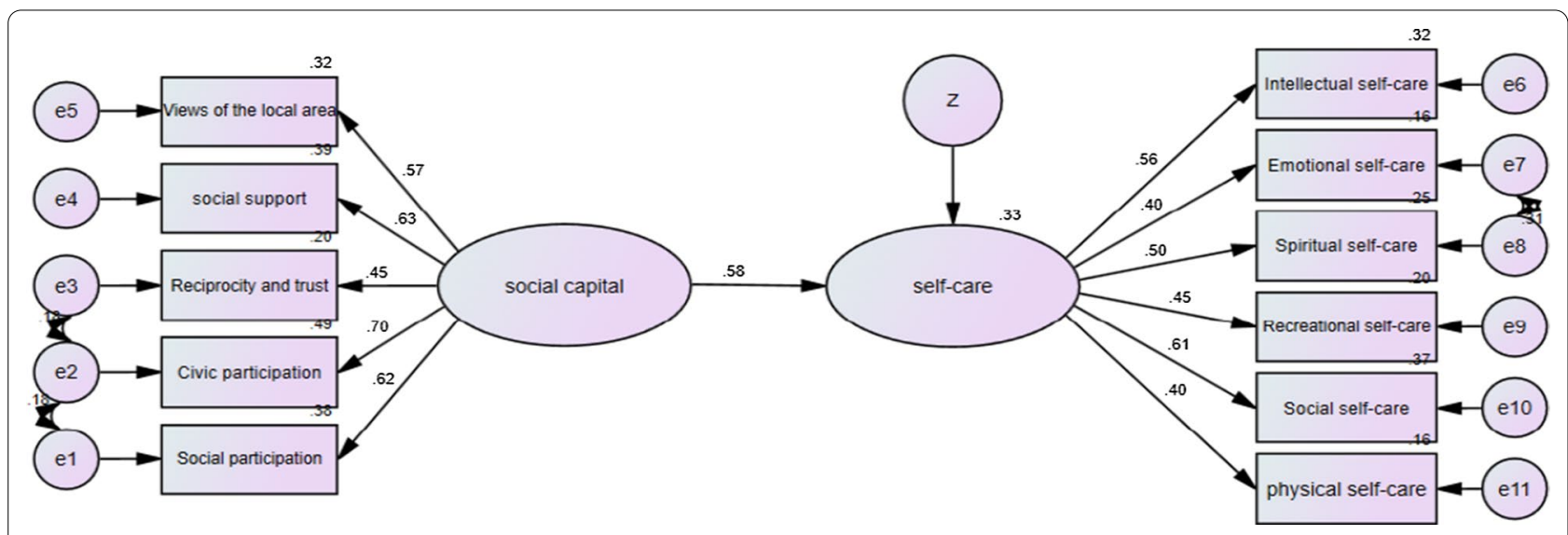

Fig. 4 The model of the relationship between social capital and self-care in the marginal parts of Yazd

Table 5 Significance of causal pathways of Structural equation model of social capital and self-care based on parts

\begin{tabular}{llllll}
\hline Part & Path & Weights & C.R & $\boldsymbol{p}$ & Result \\
\hline Marginal & $\begin{array}{l}\text { Social capital } \rightarrow \text { Self- } \\
\text { care }\end{array}$ & 0.575 & 4.667 & 0.001 & Significant \\
Middle & $\begin{array}{l}\text { Social capital } \rightarrow \text { Self- } \\
\text { care }\end{array}$ & 0.487 & 4.518 & 0.001 & Significant \\
Upper & $\begin{array}{l}\text { Social capital } \rightarrow \text { Self- } \\
\text { care }\end{array}$ & 0.617 & 4.246 & 0.001 & Significant \\
Total & $\begin{array}{l}\text { Social capital } \rightarrow \text { Self- } \\
\text { care }\end{array}$ & 0.559 & 8.284 & 0.001 & Significant \\
\hline
\end{tabular}

${ }^{* * *} p<0.001$ (two-tailed); C.R. critical ratio in the present study, the social capital of the women living in the marginal, middle and upper parts of Yazd was above the average and the women living in the middle parts of the city had the highest and the women living in the marginal parts had the lowest level of social capital $(p<0.001)$.

In Bourdieu's view, the social capital is inequitably distributed by social classes and inextricably linked to the economic and other resources in a reinforcing cycle, such that social capital can further contribute to inequalities [43].

In fact, it is the social class that affects the degree to which individuals have access to social capital. For instance, the individuals in the lower classes of the society, who are forced to live in the marginal parts due to the lack of

Table 6 The fit indices of the structural equation model of social capital and self-care

\begin{tabular}{llllllllll}
\hline Indexes & CMIN & DF & CMIN/DF & GFI & NFI & IFI & TLI & CFI & RMSEA \\
\hline Values & 333.995 & 160 & 2.087 & 0.961 & 0.921 & 0.957 & 0.940 & 0.956 & 0.027 \\
\hline
\end{tabular}


adequate economic opportunities, often have lower education and do not participate in many social and cultural affairs. Also, under the influence of the experiences of widespread inequalities in the society, a kind of pessimism towards different matters has been formed in them, and, therefore, they have low social trust. Thus, their social capital is below the other people in the society who have a better social class and opportunity to live. In contrast, the people in the middle and upper parts will be able to have constructive social relationships with others due to their higher education qualifications, better jobs and higher incomes, and because of a spirit of participation, they will have the opportunity to spend their leisure time with friends, extensive civic engagement, participation in the social and career plans, and having fun with the group. Each of which is an example of the social capital.

Our findings are in line with previous studies which also confirm a significant effect for the social capital on self-care $(\beta=0.56, p<0.001)$. Chong et al. [26] showed that the more social capital young people who live in the marginal areas of Malaysia enjoy, the more likely they are to develop the health behaviors that individuals should display. In addition, Tofani et al. [44] reported that improving the level of social capital among Brazilian women improved their health behaviors. Similarly, Marume et al. [24] showed that social capital had a significant role in improving the health of Zimbabwean asylum seekers.

Social capital consists of different dimensions one of which is social network that plays a significant role in people's health. The number of support networks and the quality of interpersonal communication in these networks can affect different aspects of people's lifestyles. For example, people who join valuable social networks are less likely to engage in abnormal social behaviors such as excessive drinking [45]. It plays a role both in maintaining the physical self-care of individuals and in promoting their social and psychological self-care by receiving emotional and social support from network members, changing people's attitudes and behaviors towards different issues, as the result of constructive interactions with others. Furthermore, social capital can influence people's self-care behavior through local norms. For example, individuals living in a specific community will be influenced by the behavioral norms of surrounding people. That is to say, if neighbours regularly participate in physical activity (e.g., jogging, cycling), it may increase the likelihood of their participation in physical exercise [46].

Furthermore, the scientific evidence shows that in order to achieve the desired level of self-care among women, a set of basic conditions (e.g. environmental conditions, individuals' social capital) are involved leading to an outcome in health through certain causal mechanisms [47]. From Bourdieu's perspective, the self-care behaviors among the women are the product of their acquired habits in the social situations they occupy. In fact, their self-care behaviors are determined by the resources (for instance, the social capital and the environmental conditions) available to them. These are among the basic conditions for the realization of self-care behaviors.

When the field (the place where women live) is mentioned, both the class position and the field's environmental and social characteristics are emphasized, which are a kind of resources, because by being in a certain environmental situation, a person is exposed to certain social and environmental factors that shape their behaviors [48]. Social capital, as one of the resources of the field, plays an important role in shaping the behavioral tendencies of self-care among women. In Bourdieu's view, women choose how to act for their self-care, but they do not have the complete freedom to do so. Their choices are limited by the strong influence of the resources (such as the social capital and the environmental conditions) available in the field [42]. The resources available in the field point to the possibility of the self-care strategies in women by shaping the mental habits (tastes and desires) of women living in the upper, middle and marginal parts of the city.

Not only do the residents of the upper parts of the city have stronger economic capital, but they also have opportunities especially social capital, separating themselves from others. The higher level of social capital for women living in the upper parts of the city provides them with a good background for constructive social relationships and access to information and emotional support. Thus, the women will be able to improve their health behaviors depending on the type of information and emotional support, and even the nature of the social network they belong to. Also, the environmental conditions have a special social meaning and can play an important role in shaping the type and the nature of women's social capital by providing the suitable opportunities such as the desired recreational-cultural atmosphere, and affect their women's self-care performance. In addition, a safe neighborhood can be a good opportunity for women to walk in and have physical activities. In this way, women can gain emotional support and constructive social interaction in order to perform better regarding their self-care $[49,50]$.

It is to be noted that there are confounding factors that can influence the effect of social capital on self-care behavior. For example, in the present research, the socioeconomic conditions influenced the individual social capital and thus are considered confounding factors [44]. Therefore, the upper, middle and marginal areas of the 
city were divided according to the economic and social characteristics to neutralize the effect of confounding factors.

Our findings showed no significant difference between the mean self-care behavior for the employed and nonemployed women living in the upper, middle and suburbs $\left(p^{>}\right.$0.05). In a similar vein, Atashpeikar et al. [51] also showed that there is no significant difference between the self-care of the employed and non-employed. On the contrary, Tabrizi et al. [52] showed that there is a significant difference between individuals' self-care ability and their employment status. This finding can be interpreted to some extent according to the cultural conditions of Iranian society. There seems to be a counterbalance to the positive and negative effects that employment or nonemployment has on self-care behavior [53]. For example, job opportunities greatly affect women's self-care behavior by expanding their social interactions, social support, financial independence, and improvement of their knowledge and skills [29]. Of course, these opportunities are created when the working environment and conditions for women are suitable because the mismatch (incompatibility) between the person and the work environment and even the experience of inequality in the workplace will lead to stress and less life satisfaction in women. On the other hand, housewives can spend more time having fun with their family members because they are solely in charge of the household, do not experience job stress, do not have to endure work-family conflict, and have more time to relax. They can therefore have better self-care. Thus, the employment or non-employment of women creates a situation that will have a positive effect on the self-care behavior of both groups.

\section{Research limitations}

Because the data were based on self-reported answers by the participants, the responses to some items might have been influenced by society values. Another limitation was the scarcity of academic literature on the relationship between social capital and self-care since the theorists do not explicitly address the relationship between social capital and self-care, but argue that social capital plays a decisive role in the individuals' health behaviors.

\section{Conclusions}

This study was an attempt to investigate the effects of social capital on the self-care practiced by women in the upper, middle and marginal areas in the city of Yazd, Iran. The two latent variables of social capital and self-care were the main components of the structural equation model in the present study. The findings indicate that social capital has a positive and significant effect on the self-care behavior of women living in the upper, middle and marginal areas of the city. The greater the amount and extent of social capital are for women, the better they will perform in self-care. Therefore, it is worthwhile to pay attention to this variable in the preparation and development of health promotion programs.

\section{Supplementary Information}

The online version contains supplementary material available at https://doi. org/10.1186/s12905-021-01469-0.

Additional file 1. Questionnaire of self-care.

\section{Acknowledgements \\ We would like to thank the cooperation of participants and the financial sup-} port of Social Welfare Studies Research Center, Yazd University.

\section{Authors' contributions}

HS: Gathered data and wrote the manuscript; AA initiated the research concept, analyzed and interpreted the data and HS and AA: edited and revised the manuscript. All authors read and approved the final manuscript.

\section{Funding}

This research was financially supported by Social Welfare Studies Research Center, Yazd University, Yazd, Iran (Grant number: 99-01-25-83/10).

\section{Availability of data and materials}

The datasets used and/or analyzed during the current study are available from the corresponding author on reasonable request.

\section{Declarations}

\section{Ethics approval and consent to participate}

The research was approved by the Ethics Committee of Yazd university affiliated with Iran National Committee for Ethics in Biomedical Research [Process No: IR.YAZD.REC.1398.032]. Informed consent was obtained from all participants. All methods were performed in accordance with the relevant guidelines and regulations of Declaration of Helsinki.

\section{Consent for publication}

Not applicable.

\section{Competing interests}

The authors report no competing interest.

Received: 27 January 2021 Accepted: 30 August 2021

Published online: 13 September 2021

\section{References}

1. Godfrey CM, Harrison MB, Lysaght R, Lamb M, Graham ID, Oakley P. Care of self-care by other-care of other: the meaning of self-care from research, practice, policy and industry perspectives. Int J Evid Based Healthc. 2011;9(1):3-24.

2. Clarke E. Self-care, coping self-efficacy and stress among graduate students in the helping professions [Ph.D. Thesis]. University of Kansas; 2017.

3. Gantz SB. Self-care: perspectives from six disciplines. Holist Nurs Pract. 1990;4(2):1-12.

4. Baker EK. Caring for ourselves: a therapist's guide to personal and professional well-being. Washington: American Psychological Association; 2003.

5. Collins WL. Embracing spirituality as an element of professional self-care. Soc Work Christ. 2005;32(3):263-74.

6. Williams-Nickelson C. Balanced living through self-care. Handbook of girls and women's psychological health. Oxford: Oxford University Press; 2006. p. 183-91. 
7. Richards K, Campenni C, Muse-Burke J. Self-care and well-being in mental health professionals: the mediating effects of self-awareness and mindfulness. J Ment Health Couns. 2010;32(3):247-64. https://doi.org/10. 17744/mehc.32.3.0n31v88304423806.

8. Jackson Jl. Self-care practices among undergraduate university students [Ph.D. Thesis]. St. Francis Xavier University; 2015.

9. Lee JJ, Miller SE. A self-care framework for social workers: building a strong foundation for practice. Fam Soc. 2013;94(2):96-103. https://doi. org/10.1606/1044-3894.4289.

10. Trinh OTH, Oh J, Choi S, To KG, Do DV. Changes and socioeconomic factors associated with attitudes towards domestic violence among Vietnamese women aged 15-49: findings from the Multiple Indicator Cluster Surveys, 2006-2011. Glob Health Action. 2016;9(1):29577.

11. Mills J, Wand T, Fraser JA. Exploring the meaning and practice of self-care among palliative care nurses and doctors: a qualitative study. BMC Palliat Care. 2018;17(1):63. https://doi.org/10.1186/s12904-018-0318-0.

12. Dugan AG, Barnes-Farrell JL. Working mothers' second shift, personal resources, and self-care. Commun Work Fam. 2020;23(1):62-79.

13. Statistical Center of Iran. International Classification of Activities for Time Use Statistics. 2016. https://www.amar.org.ir/Portals/0/News/1396/ntagv nshk93-94.pdf.

14. Un. World Happiness Report. 2019. https://www.miqols.org/resources/ WHR19.pdf

15. Garrett S. Gender (Society Now). London: Routledge; 2008.

16. Bokharaee A. Analysis of the socio-cultural factors influencing gender inequality (the study of married women $20-49$ years old in Isfahan). Socio Cult Dev Stud. 2016:4(3):59-82.

17. Ghasemi S, Delavaran A, Karimi ZM. A comparative study of the total index of mental health in males and females through meta-analysis method. Q Educ Meas. 2012;3(10):159-75.

18. Cockerham WC. Health behavior and lifestyles. Medical sociology. England: Routledge; 2017

19. Hung N, Lau LL. The relationship between social capital and self-rated health: a multilevel analysis based on a poverty alleviation program in the Philippines. BMC Public Health. 2019;19(1):1641.

20. Bourdieu P. The forms of capital. In: Richardson J, editor. Handbook of theory and research for the sociology of education. Westport: Greenwood; 1989.

21. Berkman LF, Glass T. Social integration, social networks, social support, and health. Soc Epidemiol. 2000;1:137-73.

22. Wakefield SE, Poland B. Family, friend or foe? Critical reflections on the relevance and role of social capital in health promotion and community development. Soc Sci Med. 2005;60(12):2819-32. https://doi.org/10. 1016/j.socscimed.2004.11.012.

23. Norstrand JA, Xu Q. Social capital and health outcomes among older adults in China: the urban-rural dimension. Gerontologist. 2012;52(3):325-34.

24. Marume A, January J, Maradzika J. Social capital, health-seeking behavior and quality of life among refugees in Zimbabwe: a cross-sectional study. Int J Migr Health Soc Care. 2018;14(4):377-86. https://doi.org/10.1108/ IJMHSC-04-2017-0017.

25. Hasan M. Social capital and its relationship with health-related behaviors in rural Uttar Pradesh. India: Johns Hopkins University; 2019.

26. Chong ST, Koh D, Nazri YFM, Ibrahim F, Rahim SA. Social capital and well-being among marginalized young Malaysians. Kasetsart J Soc Sci. 2020;41(1):176-80.

27. Afshani SA, Fallah H, Shiri Mohammadabad H, Heddat E, Malja SN. Assessing the quality of urban life in neighborhoods of Yazd. In: Municipality Yazd; 2019.

28. Harper R. The measurement of social capital in the United Kingdom. Off Natl Stat. 2002;11:2019.

29. Dorociak KE. Development of the personal and professional self-care scale [Ph.D. Thesis]. Loyola University Chicago; 2015.

30. The Institute for Functional Medicine. Self-Care Questionnaire. 2016. https://static1.squarespace.com/static/581a52ff414fb5c2f581b403/t/ 59d6c0bfd7bdce90d546a3c3/1507246271211/Self-Care+Questionnaire. pdf.

31. Saakvitne KW, Pearlman LA. Transforming the pain: a workbook on vicarious traumatization. New York: WW Norton \& Co; 1996.
32. Goncher ID, Sherman MF, Barnett JE, Haskins D. Programmatic perceptions of self-care emphasis and quality of life among graduate trainees in clinical psychology: the mediational role of self-care utilization. Train Educ Prof Psychol. 2013;7(1):53. https://doi.org/10.1037/a0031501.

33. Fleshner F. Physical activity and stress resistance: sympathetic nervous system adaptations prevent stress-induced immunosuppression. Exerc Sport Sci Rev. 2005;33(3):120-6. https://doi.org/10.1097/00003677-20050 7000-00004.

34. Rose J, Glass N. An Australian investigation of emotional work, emotional well-being and professional practice: an emancipatory inquiry. J Clin Nurs. 2010;19(9-10):1405-14. https://doi.org/10.1111/j.1365-2702.2009. 02997.x.

35. Tanyi RA. Towards clarification of the meaning of spirituality. J Adv Nurs. 2002;39(5):500-9. https://doi.org/10.1046/j.1365-2648.2002.02315.x.

36. Norcross J, Guy J. Leaving it at the office: a guide to psychotherapist selfcare. New York, USA: The Guilford Press; 2007.

37. Snelgrove JW, Pikhart H, Stafford M. A multilevel analysis of social capital and self-rated health: evidence from the British Household Panel Survey. Soc Sci Med. 2009;68(11):1993-2001.

38. Gonzalez R, Fuentes A, Muñoz E. On social capital and health: the moderating role of income inequality in comparative perspective. Int J Sociol. 2020;50(1):68-85.

39. Pearce N, Davey SG. Is social capital the key to inequalities in health? Am J Public Health. 2003;93(1):122-9.

40. Poortinga W. Social capital: an individual or collective resource for health? Soc Sci Med. 2006;62(2):292-302.

41. Cockerham WC. Social causes of health and disease. Cambridge: Polity; 2007

42. Williams SJ. Theorising class, health and lifestyles: can Bourdieu help us? Sociol Health IIIn. 1995; 17(5):577-604.

43. Mithen J, Aitken Z, Ziersch A, Kavanagh AM. Inequalities in social capital and health between people with and without disabilities. Soc Sci Med. 2015;126:26-35.

44. Tofani AA, de Almeida LG, Sheiham A, Vettore MV. The different effects of neighbourhood and individual social capital on health-compromising behaviours in women during pregnancy: a multi-level analysis. BMC Public Health. 2015;15(1):890. https://doi.org/10.1186/s12889-015-2213-4.

45. Turner B. Social capital, inequality and health: the Durkheimian revival. Soc Theory Health. 2003;1(1):4-20.

46. Mohnen SM, Völker B, Flap H, Groenewegen PP. Health-related behavior as a mechanism behind the relationship between neighborhood social capital and individual health - a multilevel analysis. BMC Public Health. 2012;12(1):1-12.

47. Falleti TG, Lynch JF. Context and causal mechanisms in political analysis. Comp Polit Stud. 2009;42(9):1143-66.

48. Macintyre S, Ellaway A, Cummins S. Place effects on health: how can we conceptualise, operationalise and measure them? Soc Sci Med. 2002;55(1):125-39.

49. Andrulis D. Inner city health care. Philadelphia: American College of Physicians; 1997

50. Haskell WL, Lee I-M, Pate RR, Powell KE, Blair SN, Franklin BA, et al. Physical activity and public health: updated recommendation for adults from the American College of Sports Medicine and the American Heart Association. Circulation. 2007;116(9):1081. https://doi.org/10.1249/mss.0b013 e3180616b27.

51. Atashpeikar S, Jalilazar T, Heidarzadeh M. Self-care ability in hemodialysis patients. J Caring Sci. 2012;1(1):31.

52. Tabrizi JS, Behghadami MA, Saadati M, Söderhamn U. Self-care ability of older people living in urban areas of northwestern Iran. Iran J Public Health. 2018;47(12):1899.

53. Ahmadnia S. Employment effects on women health. Soc Welf. 2004:3(12):157-80.

\section{Publisher's Note}

Springer Nature remains neutral with regard to jurisdictional claims in published maps and institutional affiliations. 